\title{
ESTUDIO TAXONÓMICO Y ARQUEOLÓGICO DE LA COLECCIÓN DE MALACOFAUNA PROCEDENTE DE LA COLONIA AUGUSTA EMERITA (MÉRIDA) CON ESPECIAL ATENCIÓN AL USO DE PECTEN MAXIMUS EN EL TOCADOR DE LA MUJER ROMANA
}

\author{
TAXONOMIC AND ARCHAEOLOGICAL STUDY OF THE COLLECTION \\ OF MALACOFAUNA FROM THE COLONY AUGUSTA EMERITA (MÉRIDA) \\ WITH SPECIAL ATTENTION TO THE USE OF PECTEN MAXIMUS \\ IN THE TOILET OF THE ROMAN WOMAN
}

\section{Nova BARRERO MARTÍN ${ }^{1}$ - Rafael ARAUJO ARMERO²}

RESUMEN: Este trabajo presenta un análisis taxonómico de la colección de malacofauna del Museo Nacional de Arte Romano de Mérida (en adelante MNAR), un repertorio interesante desde el punto de vista histórico, ya que prácticamente en su totalidad está inédita. El estudio centra además su análisis en el caso específico de los ejemplares de Pecten maximus (L, 1758), cuyo uso parece estar asociado de manera recurrente al ámbito de la toilette de la mujer romana, con ejemplos muy destacados de reproducciones en materiales nobles, como plata o ámbar.

PALABRAS CLAVE: Arqueomalacología. Colonia Augusta Emerita. Museo Nacional de Arte Romano. Toilette de la mujer romana. Pecten maximus.

ABSTRACT: This paper presents a taxonomic analysis of the collection of malacofauna of the National Museum of Roman Art of Mérida, an interesting collection from the historical point of view, since practically in its totality it is unpublished. This work also focuses its analysis on the specific case of the specimens of Pecten maximus (L, 1758),

\footnotetext{
${ }^{1}$ Museo Nacional de Arte Romano (Mérida, España). nova.barrero@cultura.gob.es ORCID ID: https: / / orcid.org/0000-0003-1914-8999.

2 Museo Nacional de Ciencias Naturales-C.S.I.C. (Madrid, España). rafael@mncn.csic.es ORCID ID: https:/ / orcid.org/0000-0001-5842-666.

El presente artículo se integra dentro de los trabajos desarrollados en el marco del Proyecto de Investigación I+D Nacional "Proyecto I+D 'Augusta Emerita y los Inicios de la Provincia Romana de Lusitania en Época de Augusto'” (2015-2017, HAR2014-52958-P), financiado por el Ministerio de Ciencia, Innovación y Universidades.
} 
whose use seems to be associated in a recurrent way with the toilette of the Roman woman, with very outstanding examples of noble materials such as silver or amber.

KEYWORDS: Archaeo-Malacology. Colony Augusta Emerita. National Museum of Roman Art. Toilette of the Roman Woman. Pecten maximus.

\section{LA COLECCIÓN MALACOLÓGICA EN EL MNAR}

La colección de moluscos del MNAR ha sido determinada por el conservador de malacología del Museo Nacional de Ciencias Naturales, coautor de esta publicación. Está compuesta por un total de 50 individuos, 14 gasterópodos (tabla 1) y 36 bivalvos (tablas 2, 3 y 4). Entre los bivalvos, destaca la alta representación de Pecten maximus (L, 1758), con un total de 13 (tabla 4), de los cuales 4 conservan ambas valvas.

Esta sección de las colecciones del Museo tiene como dificultad de estudio la ausencia de documentación relevante o específica sobre su contexto de hallazgo, ya que los ejemplares proceden de intervenciones arqueológicas antiguas que no se documentaron de forma sistemática en los trabajos de campo, pues no se especifica en su registro lugar exacto de su hallazgo, situación, relación estratigráfica, etc. Fueron, en muchos casos, ejemplares seleccionados por sus recolectores basándose en criterios como su buen estado de conservación o singularidad.

\section{GASTERÓPODOS}

Las grandes caracolas del género Charonia, modificadas mediante un orificio en el apéndice, pueden ser empleadas como instrumentos musicales. Así lo refiere Plinio, quien nombra la especie bucinum, utilizada como trompeta (Plin. Nat. 9, 130). En los yacimientos vesubianos se han documentado numerosos ejemplares de Charonia nodifera (Lamarck, 1822) y Charonia sequenzae (Aradus et Banoit, 1872) con el apéndice modificado para servir como trompetas (Reese, 2002: 293). En el primer caso se trata de una sinonimia de Charonia lampas (L, 1758), y en el segundo, de una sinonimia de Charonia variegata (Lamarck, 1816). También se ha citado un ejemplar modificado de Euthria cornea (Reese, 2002: 296). La especie Charonia lampas pertenece a la familia Charoniidae, mientras que Euthria cornea (L, 1758) pertenece a la familia Buccinidae. Destacan también los tres individuos de Charonia documentados en el puerto de Cádiz, modificados entrópicamente para su uso como aerófonos (Sáez Romero y Gutiérrez López, 2014).

En el caso de los ejemplares emeritenses, no ha podido ser documentada ninguna modificación en los mismos, por lo que su presencia en los distintos contextos se explica relacionándolo con el coleccionismo privado, cuyo exotismo en el interior de la provincia de Lusitania debía ser apreciado. Augusta Emerita, como capital administrativa de la provincia, era eje principal de la red viaria en el sur- 
oeste peninsular (Gil Mantas, 2015: 109-118) y las conexiones con Olisipo, el puerto por antonomasia de la provincia (Fabiáo, 2014: 74-75), estaban bien fijadas. El abastecimiento de la colonia de todo tipo de mercancías exóticas debió justificarse por su papel preponderante desde el punto de vista político y administrativo.

Por otro lado, están representadas las especies Hexaplex trunculus (L, 1758) con 4 ejemplares (fig. 1) y Stramonita haemastoma (L, 1767), con 2 ejemplares (fig. 2). Am-

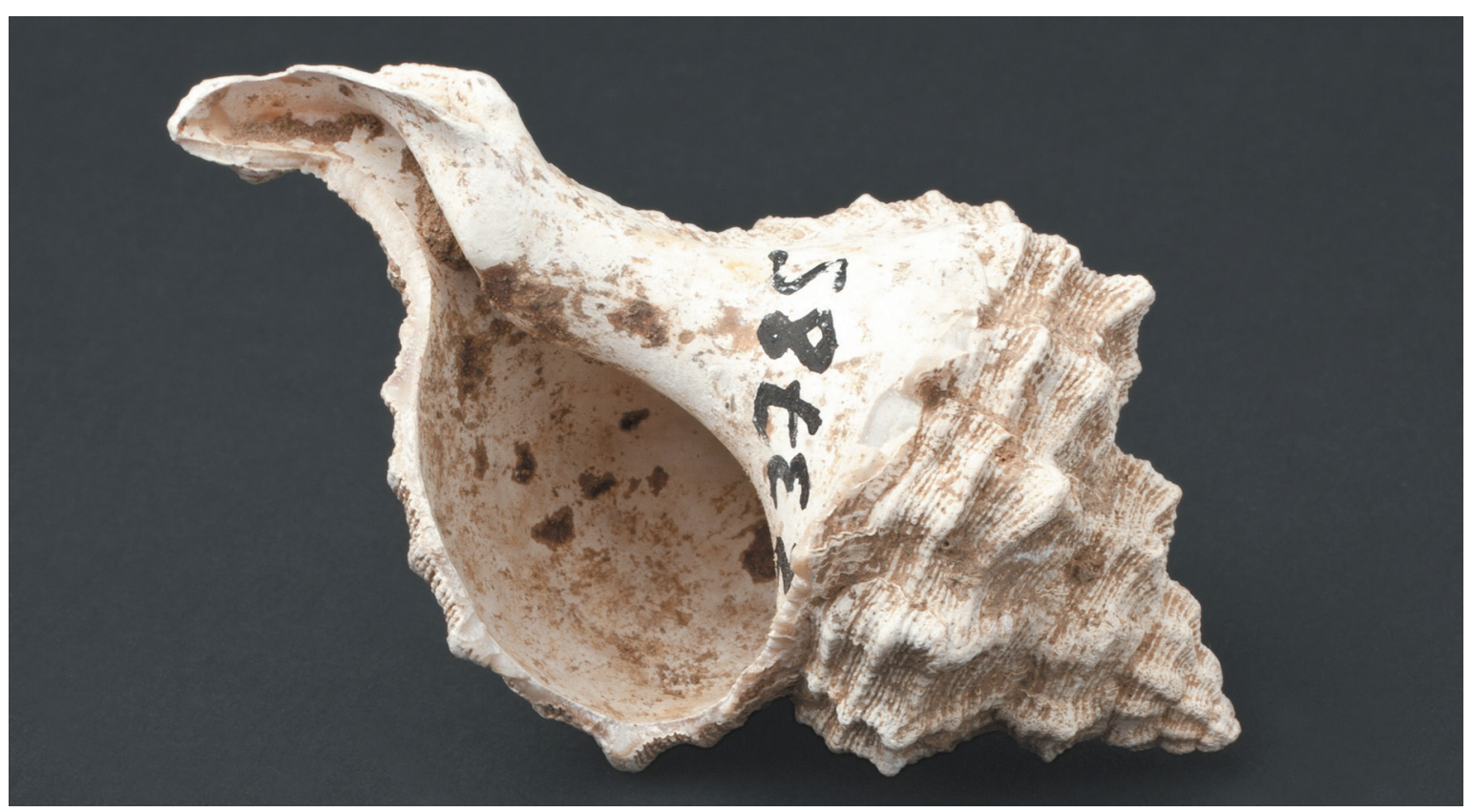

Fig. 1

Ejemplar de Hexaplex trunculus (L.), $\mathrm{n}^{\mathrm{o}}$ inv. CE23785. Foto: Archivo MNAR.

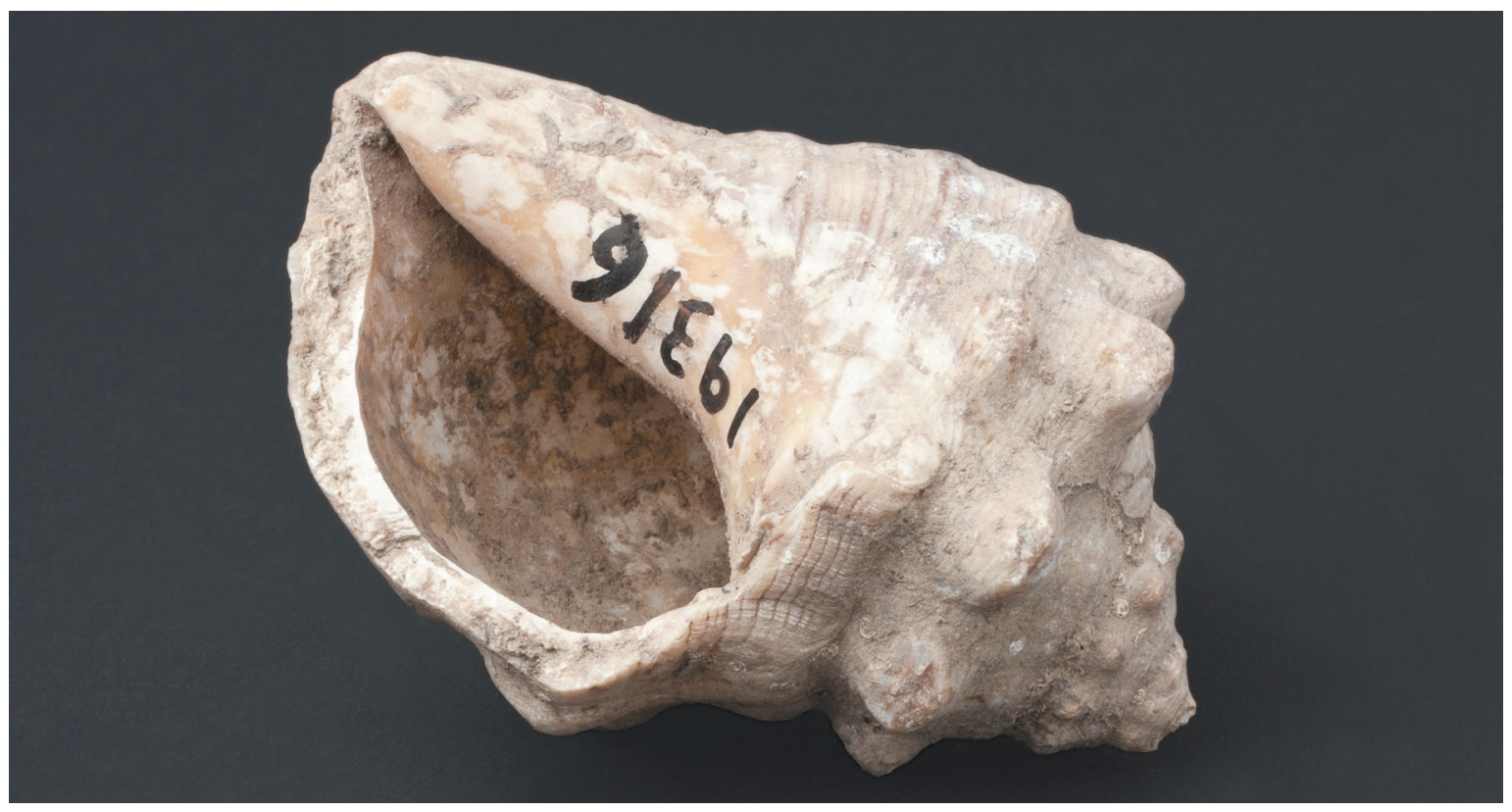

Fig. 2

Ejemplar de Stramonita haemastoma (L.), nº inv. CE19316. Foto: Archivo MNAR. 
bas especies son bien conocidas en la Antigüedad por ser empleadas para la obtención de la púrpura (Fernández Uriel, 2009: 85-96), un producto ligado al lujo en Roma, ya que su uso reservado para la significación social (Alfaro Giner, 2013: 7598) elevó a altísimos precios el producto de tintura, cuya tradición aristocrática en el Mediterráneo se remonta a la época creto-micénica (Alfaro Giner y Tébar Megías, 2004: 195-210).

El escaso número de ejemplares identificados (6) y la no modificación antigua de su superficie, lleva a interpretar su presencia en el contexto emeritense quizás con un uso culinario o decorativo, más que dentro de una producción del tinte.

Este ha sido también el caso de Pompeya, donde se han reconocido un total de 102 ejemplares de Murex brandaris (L, 1758), sinonimia de Bolinus brandaris (L, 1758), y 42 de Murex trunculus (L, 1758), sinonimia de Hexaplex trunculus, algunos de ellos relacionados con la decoración de fuentes y ninfeos. Como ocurre en las muestras de Mérida, su presencia no se ha relacionado con las actividades destinadas a la producción de púrpura, entre otros argumentos, por el escaso número de ejemplares (Reese, 2002: 298) si se compara con los ejemplares necesarios para la obtención de tan preciado producto.

Finalmente, dentro de los gasterópodos, destaca un opérculo de Bolma rugosa (L, 1767) (fig. 3), una pieza sin duda singular y que debido a sus características pudo ser conservado dentro de una colección particular o servir como amuleto, incluso como adorno personal, ya que estos opérculos siguen siendo hoy objeto de especial significación para adornos, collares y pendientes. En el solar de la colonia donde se ha encontrado este opérculo, solo había sido publicado, hasta el momento, la aparición dentro de un depósito funerario femenino de época altoimperial un ejemplar de Cypraea pantherina, Lightfoot, 1786, de origen indopacífico e interpretada como amuleto (Rodríguez-Hidalgo et al., 2013: 183-193).

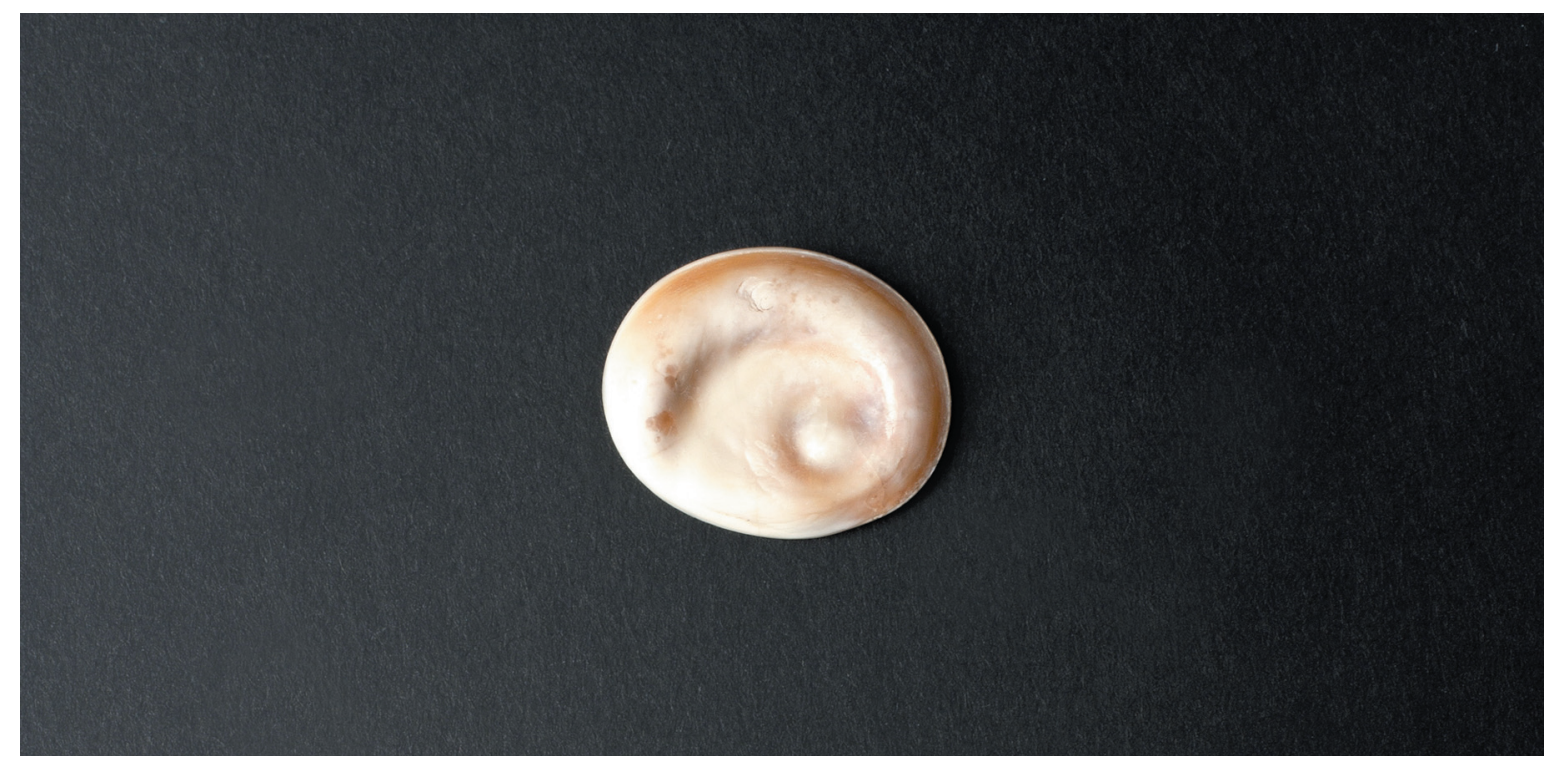

Fig. 3

Opérculo de Bolma rugosa (L.), no inv. CE13538. Foto: Archivo MNAR. 


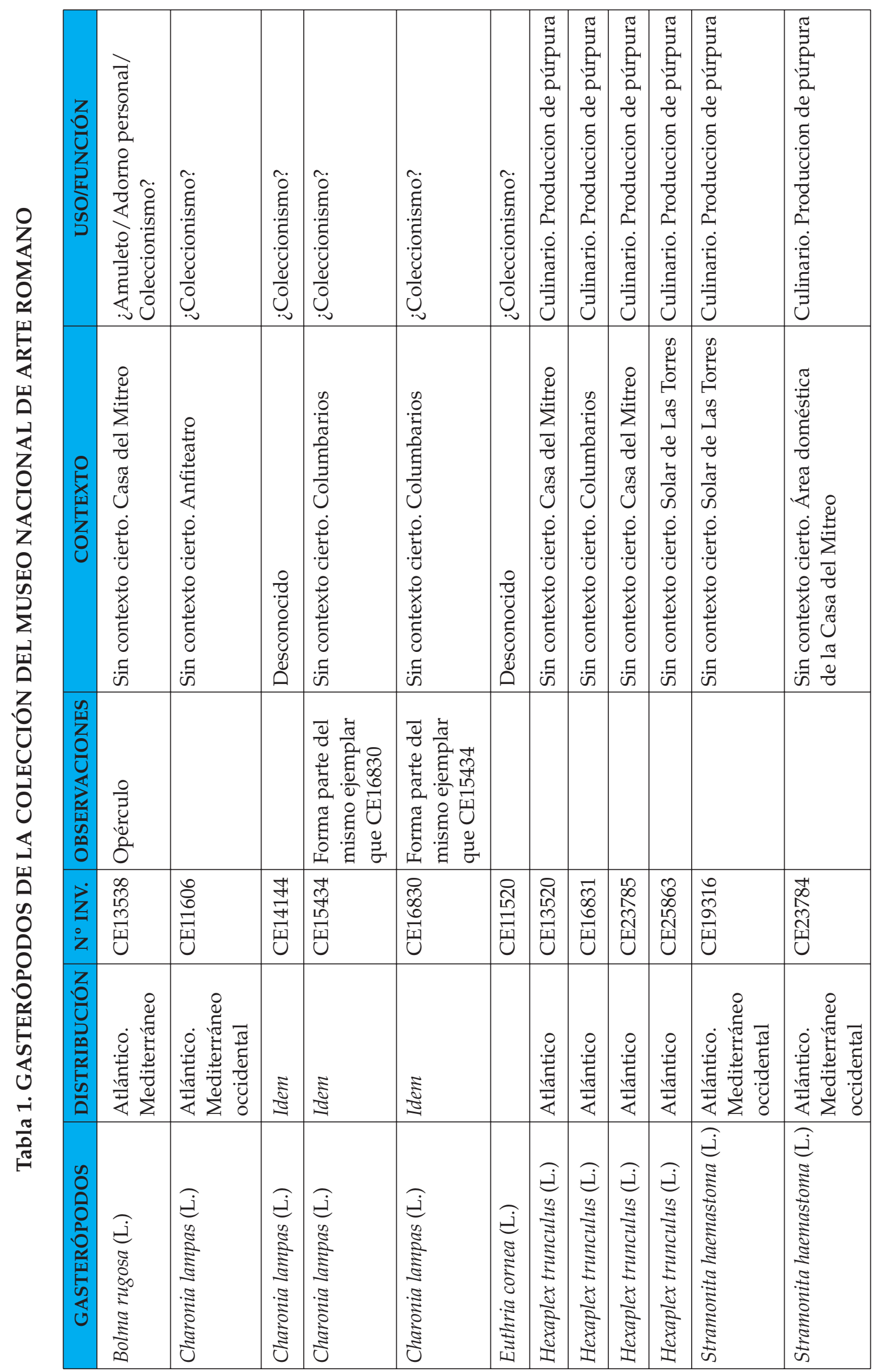




\section{BIVALVOS}

En la colección del MNAR se han identificado 4 ejemplares de Acanthocardia tuberculata (L, 1758). En Pompeya y Herculano se han catalogado un buen número de ejemplares (56 valvas), bien formando parte de la decoración parietal de ninfeos y espacios abiertos, como el Ninfeo de la Casa de Neptuno y Anfitrite (fig. CXX), bien horadados en el umbo e interpretados para servir como colgante y adorno personal; otros ejemplares de esta misma especie pudieron servir de contenedores de pigmentos, quizás para cosméticos (Reese, 2002: 299-300).

Asimismo, pertenecen a la colección 4 ejemplares de Glycymeris violacescens (Lamarck, 1819). Especial interés presenta la valva con $n^{\circ}$ inv. 6490 (fig. 4), que formaba parte del ajuar hallado en el área conocida como "Viviendas protegidas", que posteriormente se tratará con mayor profundidad. Este ejemplar tiene perforado el umbo, por lo que posiblemente fuera empleado como elemento de adorno personal. En los yacimientos vesubianos destaca también este uso como ornamento, pues de las 57 valvas identificadas, 15 presentan orificio en el umbo (Reese, 2002: 300301). Creemos que este sería el caso del ejemplar CE6490 procedente del ajuar de la necrópolis de "Viviendas protegidas".

Igualmente se han identificado 3 ejemplares de Laevicardium oblongum (Gmelin, 1791) y 1 ejemplar de Laevicardium sp.

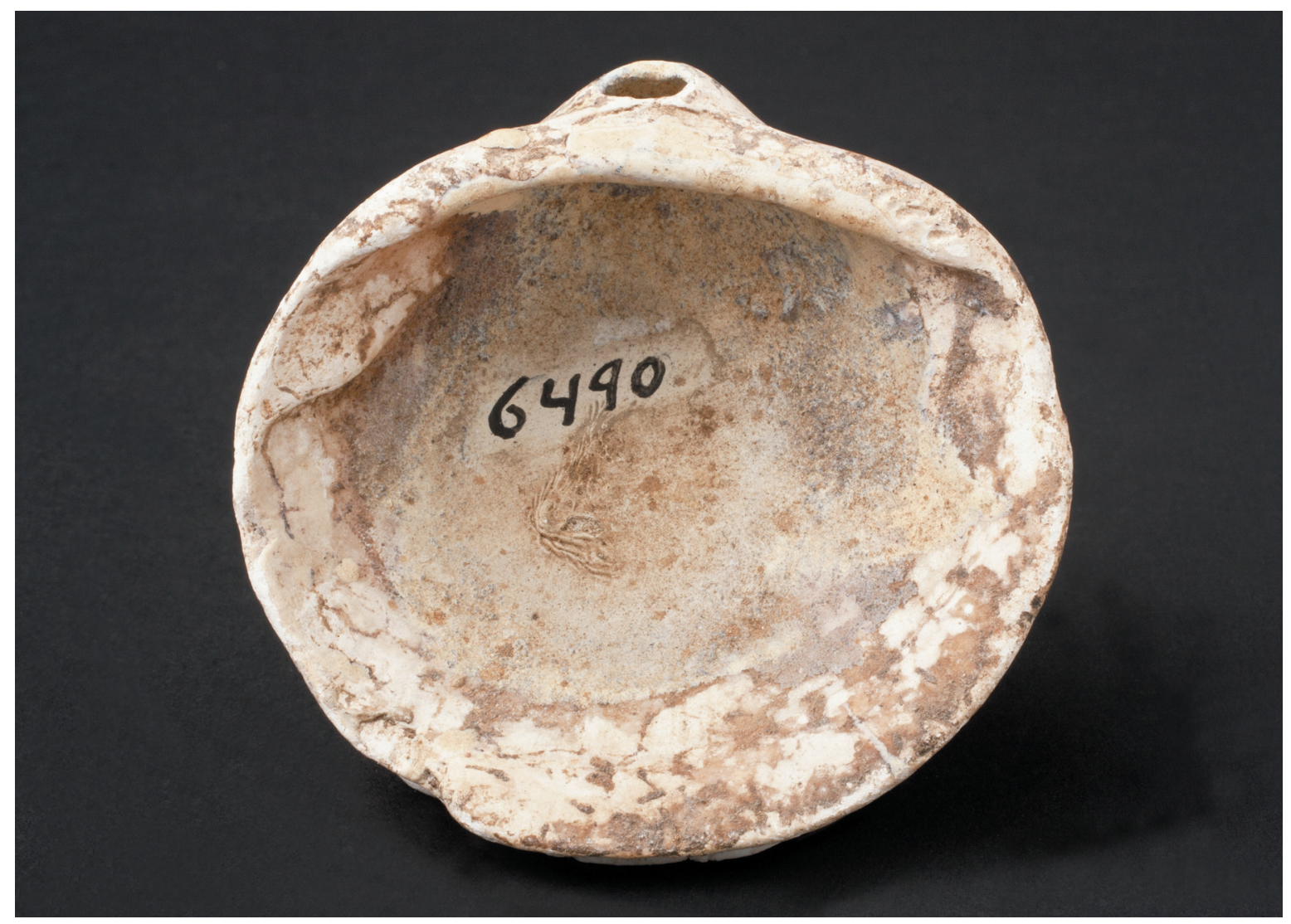

Fig. 4

Ejemplar de Glycymeris violacescens (Lamarck, 1819), $\mathrm{n}^{\circ}$ inv. CE6490. Foto: Archivo MNAR. 


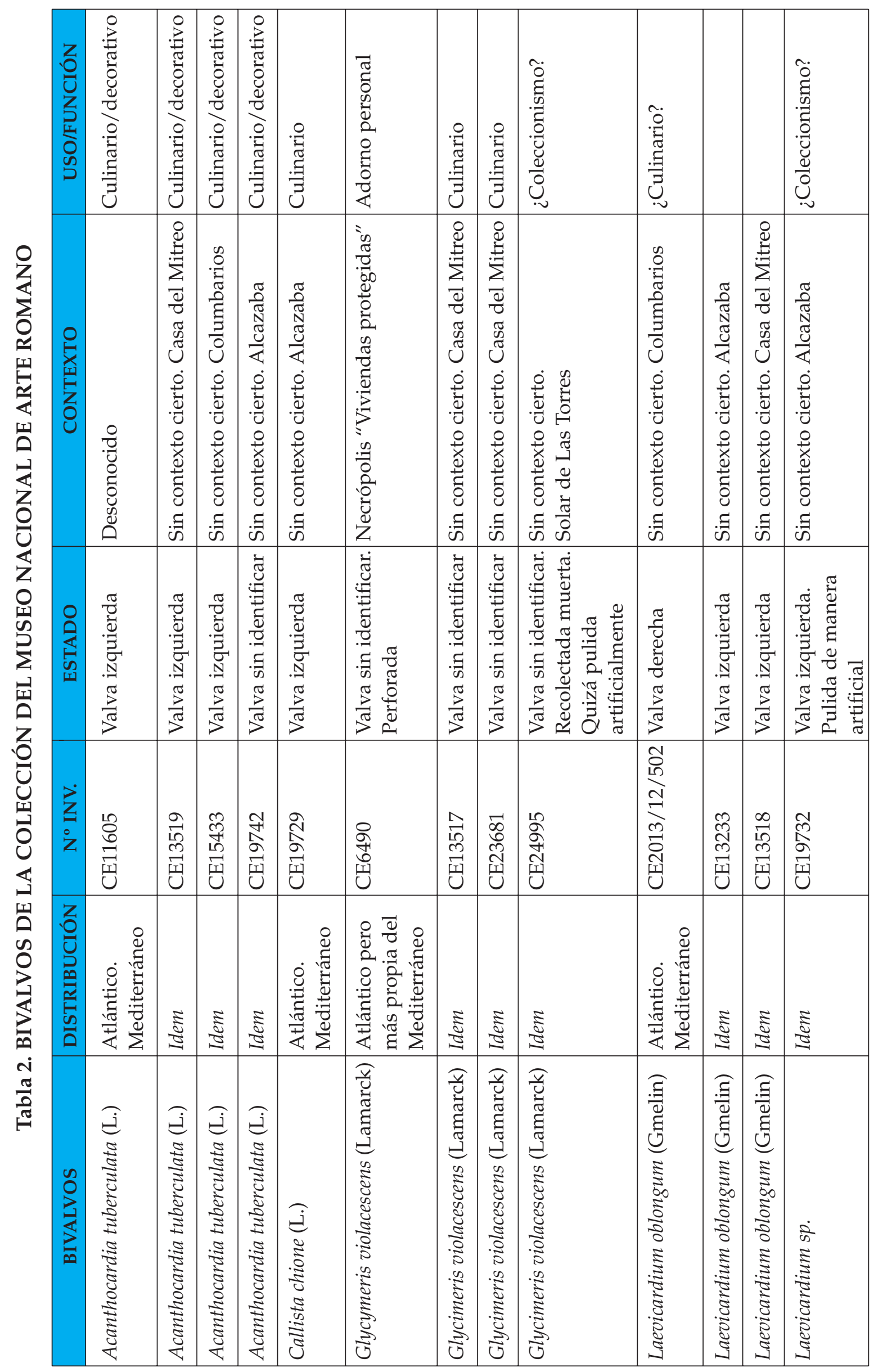


Forman parte de la colección del MNAR 10 valvas correspondientes a 9 individuos de Ostrea edulis (L, 1758) (tabla 3) (figs. 5a y b), cuyo empleo en el arte culinario romano es muy reconocido. De la necrópolis del Albarregas proceden el ejemplar completo y dos valvas más ( $n^{\circ}$ inv. 7980, 7981, 7982 y 7983), aunque no se ofrece más detalle que el hecho de que uno de los ejemplares formase parte del depósito de una de las tumbas identificadas correspondiente a un individuo infantil (Álvarez Sáenz de Buruaga, 1952: 140). Además, dos ejemplares proceden de las excavaciones de la basílica de Casa Herrera, uno de ellos citado en el inventario como "concha de río" (Caballero y Ulbert, 1976: 132).

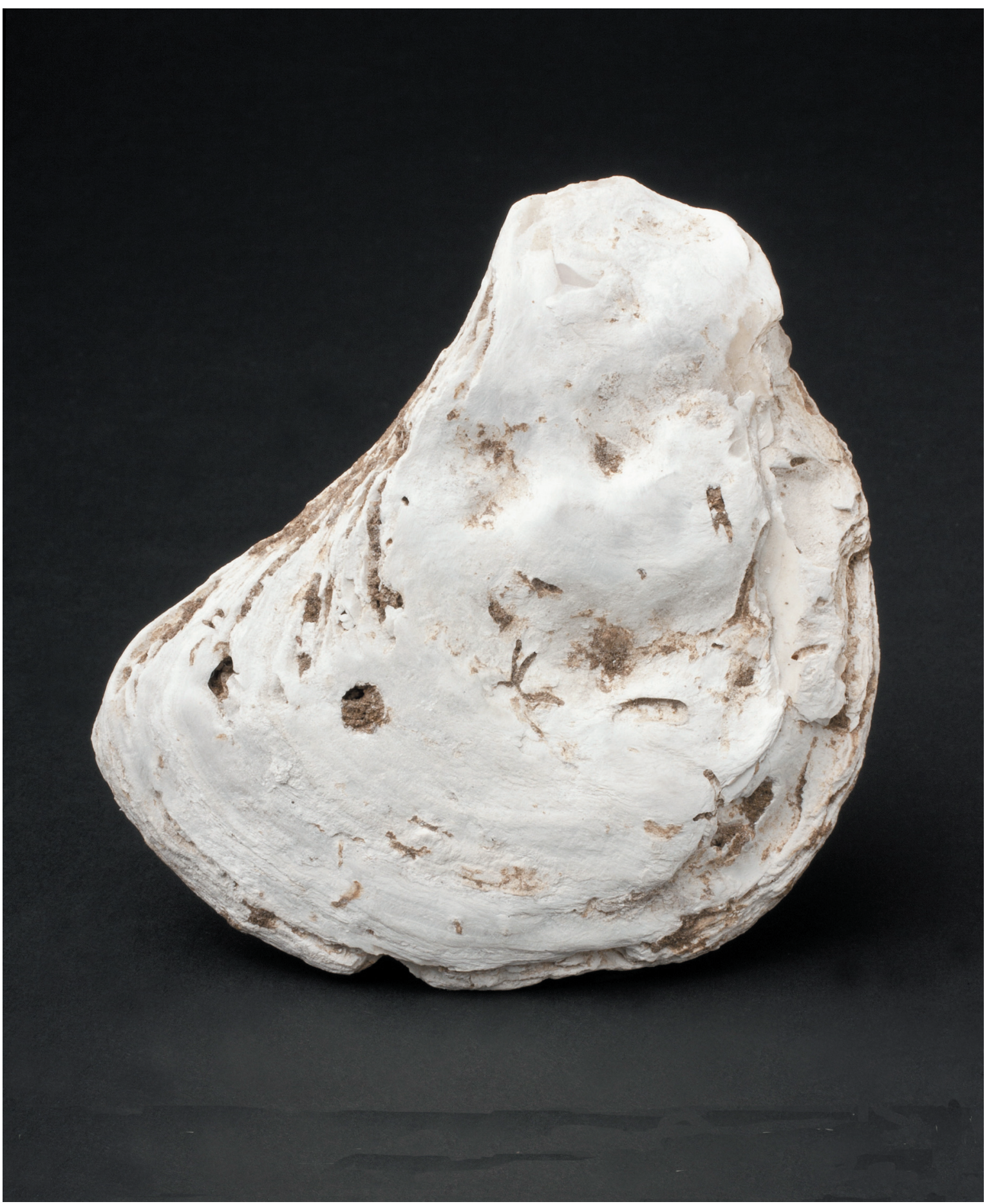




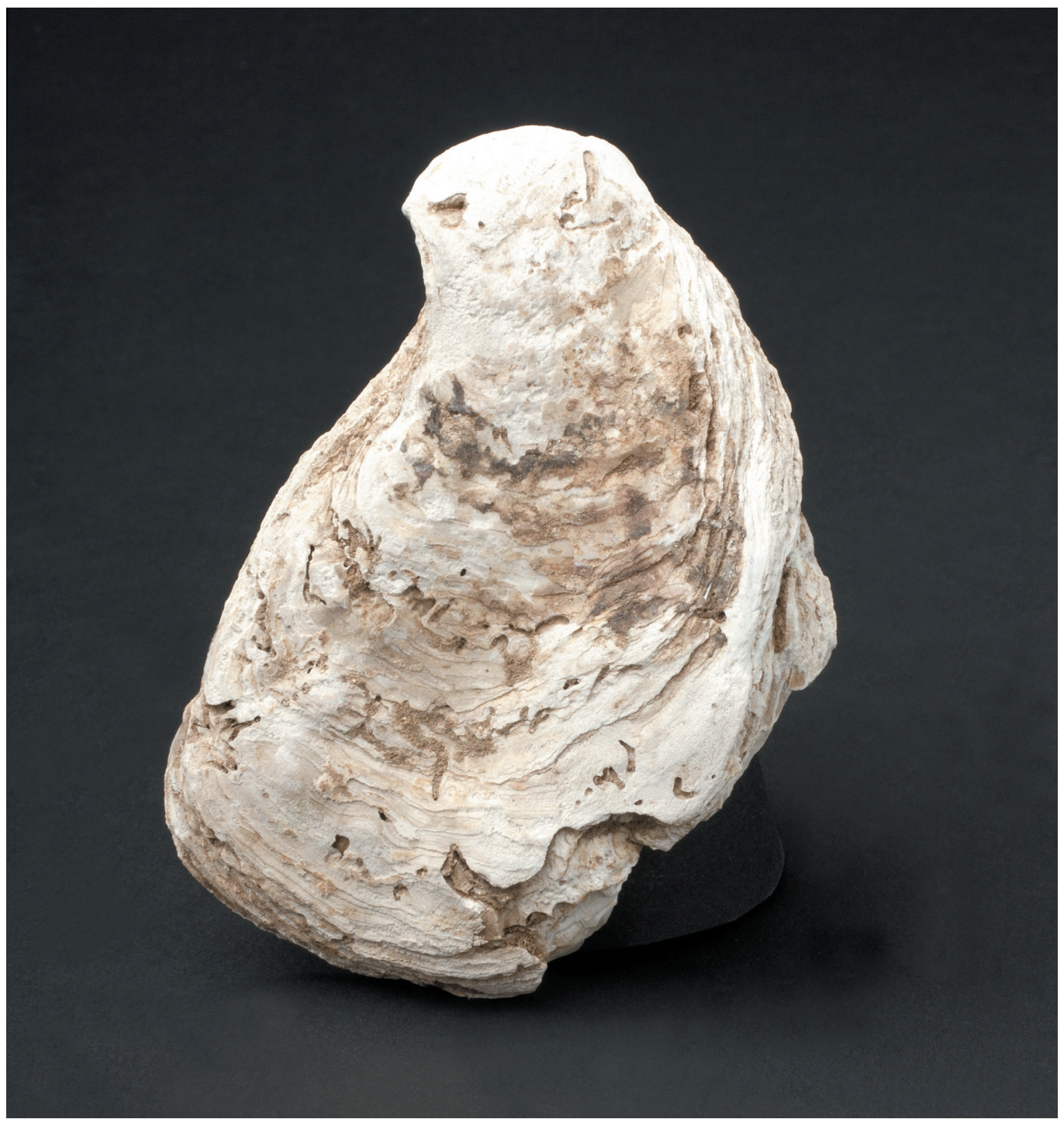

Figs. $5 a$ y $b$

Ejemplares de Ostrea edulis (L.), no inv. CE7980 y CE7981. Foto: Archivo MNAR.

Las ostras fueron empleadas tanto como manjar exquisito dentro de la alta cocina romana (Finet y Olive, 2004: 109) como en medicina (Plin. Nat. 32, 59-64). Plinio afirma la existencia ya en el siglo II a.C. de viveros de Ostrea y cómo este era un negocio muy lucrativo (Plin. Nat. 9, 168).

Pero dentro de la colección malacológica del Museo de Mérida destacan sin duda los ejemplares de Pecten maximus, con 13 individuos identificados de los que 4 de ellos conservan ambas valvas (tabla 4). Su destacada representación tanto en número como en contextos documentados, así como la manipulación realizada sobre ellos para su uso concreto como contenedores en el ámbito de la toilette de la mujer romana, requiere de un análisis específico. 


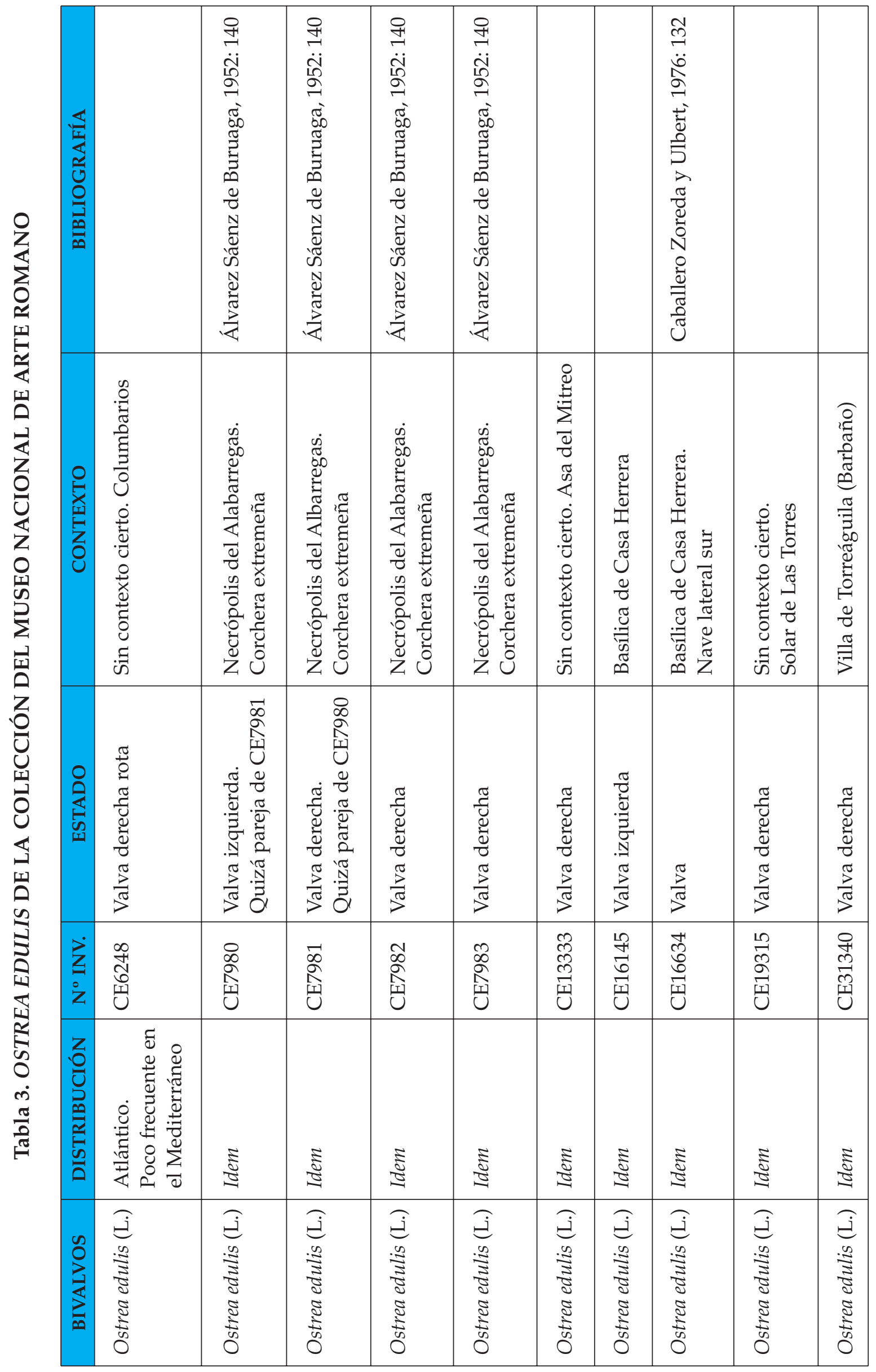




\section{USO DE PECTEN MAXIMUS EN EL TOCADOR DE LA MUJER ROMANA}

La especie de bivalvo Pecten maximus tiene un concha sólida, inequivalva y equilateral, con dos lengüetas laterales dorsales. La valva derecha es convexa y la izquierda plana o algo cóncava hacia el vértice. Presenta un contorno más largo que alto y una longitud media de $170 \mathrm{~mm}$. Tiene 15 a 17 costillas radiales anchas de cantos suaves con estrías y líneas concéntricas mezcladas con estrías de crecimiento en las dos valvas. Su coloración es blanca con manchas más tenues de diferentes colores en la valva derecha y blancuzca con manchas color crema, rosa o rojo, en bandas o en zigzag, en la izquierda. Vive en fondos de arena y cascajo del piso infralitoral. Su distribución abarca desde el norte de Europa hasta el sur de España, también en Azores, Madeira y Canarias, siendo muy rara en el Mediterráneo (Gofas, Moreno y Salas, 2011).

16 La especie similar Pecten jacobaeus (L, 1758) es muy similar pero se diferencia por el tipo de costillas, que vistas desde el borde frontal son angulosas. Mide 160 mm. Vive en el Atlántico y en el Mediterráneo (Gofas, Moreno y Salas, 2011).

De los 13 individuos identificados en la colección del MNAR, destacan aquellos de los cuales se conserva documentación sobre su hallazgo y contexto arqueológico, relacionándose todos ellos con un depósito funerario correspondiente a una mujer. Además, en cuatro de los cinco casos, que a continuación se analizarán, conservan las dos valvas. Uno de ellos presenta una modificación antrópica con el fin, como se observará, de servir de contenedor, probablemente para productos cosméticos, dentro de los objetos relacionados con la toilette femenina.

Inv. CE5745. Bivalvo completo (fig. 6).

Necrópolis oriental. Zona de El Silo. Siglo I d.C.

Álvarez Sáenz de Buruaga, 1946: 5.

18 La pieza forma parte de un numeroso depósito funerario perteneciente a una de las tres tumbas con ajuar que fueron recuperadas por la Comisaría General de Excavaciones en 1945 (Álvarez Sáenz de Buruaga, 1946: 4). En concreto, la tumba $\mathrm{n}^{\circ} 3$ contenía un ajuar compuesto por 53 piezas bien relacionadas por el autor mencionado (fig. 7). Buena parte de este depósito está expuesto en el Museo, gracias a los trabajos realizados por el conservador R. Sabio.

19 Entre el numeroso conjunto, destacan las piezas relacionadas con el adorno personal, como el entalle con figura de Minerva ( $\mathrm{n}^{\circ}$ inv. 5743), una pareja de piezas de bronce identificadas como pendientes $\left(\mathrm{n}^{\circ}\right.$ inv. 5800 y 5801) y una fíbula de arco que ha perdido la aguja ( $\mathrm{n}^{\circ}$ inv. 5787). Otro grupo de objetos debe estar relacionado con la hilatura, como los husos de hueso ( $n^{\circ}$ inv. 5740, 5741 y 5742) y las fusayolas en vidrio ( $\mathrm{n}^{\circ}$ inv. 5797 y 5798), incluso quizá la hoja de cuchillo de hierro ( $\mathrm{n}^{\circ}$ inv. 5775) (Sabio González, 2012: 46) pudiera haber formado parte del utillaje propio de esta actividad ligada directamente al ámbito de la mujer. Finalmente, destacamos otro grupo de piezas relacionados con la toilette femenina, como la coticula de pizarra 


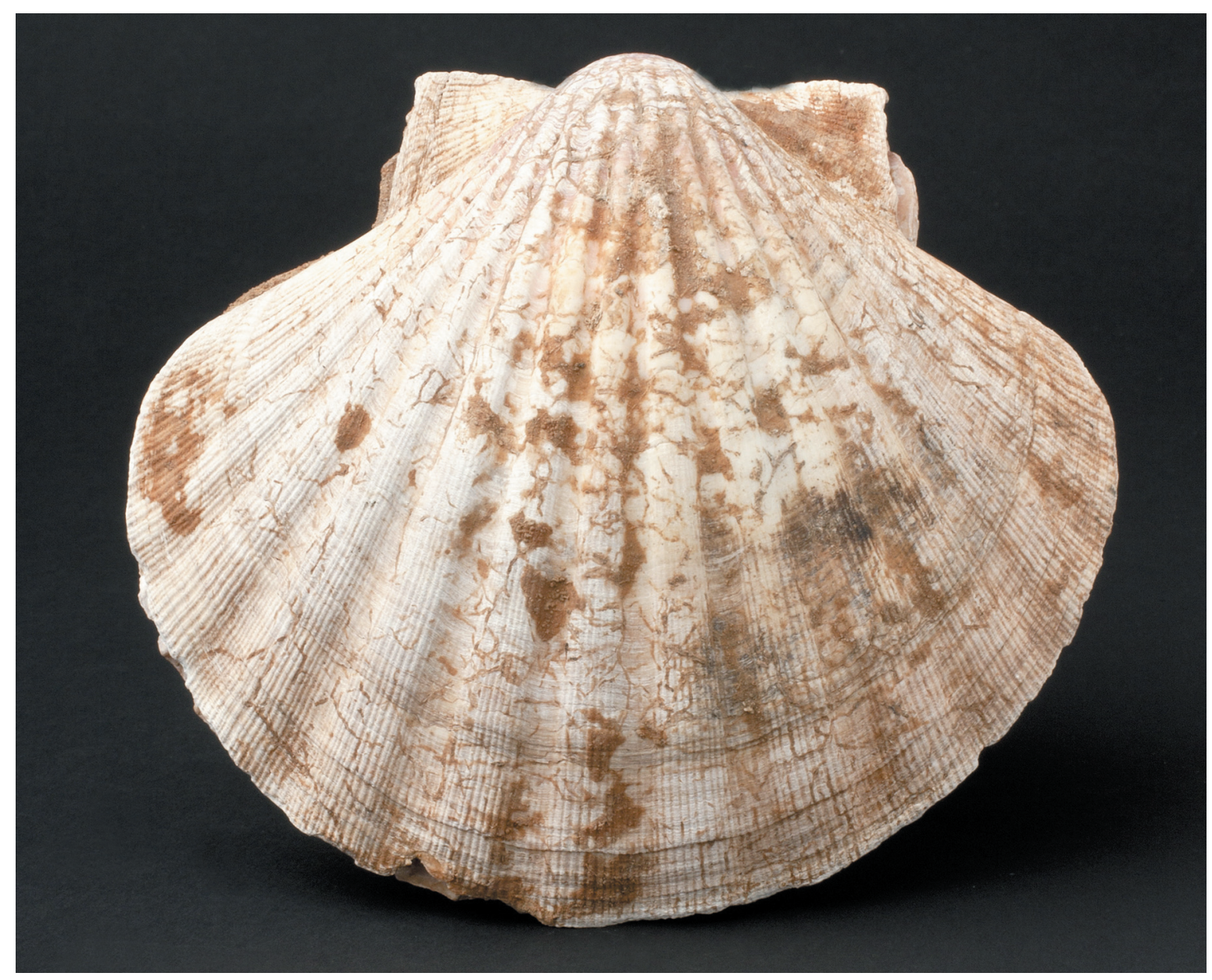

Fig. 6

Pecten maximus (L.), $\mathrm{n}^{\circ}$ inv. CE5745. Foto: Archivo MNAR.

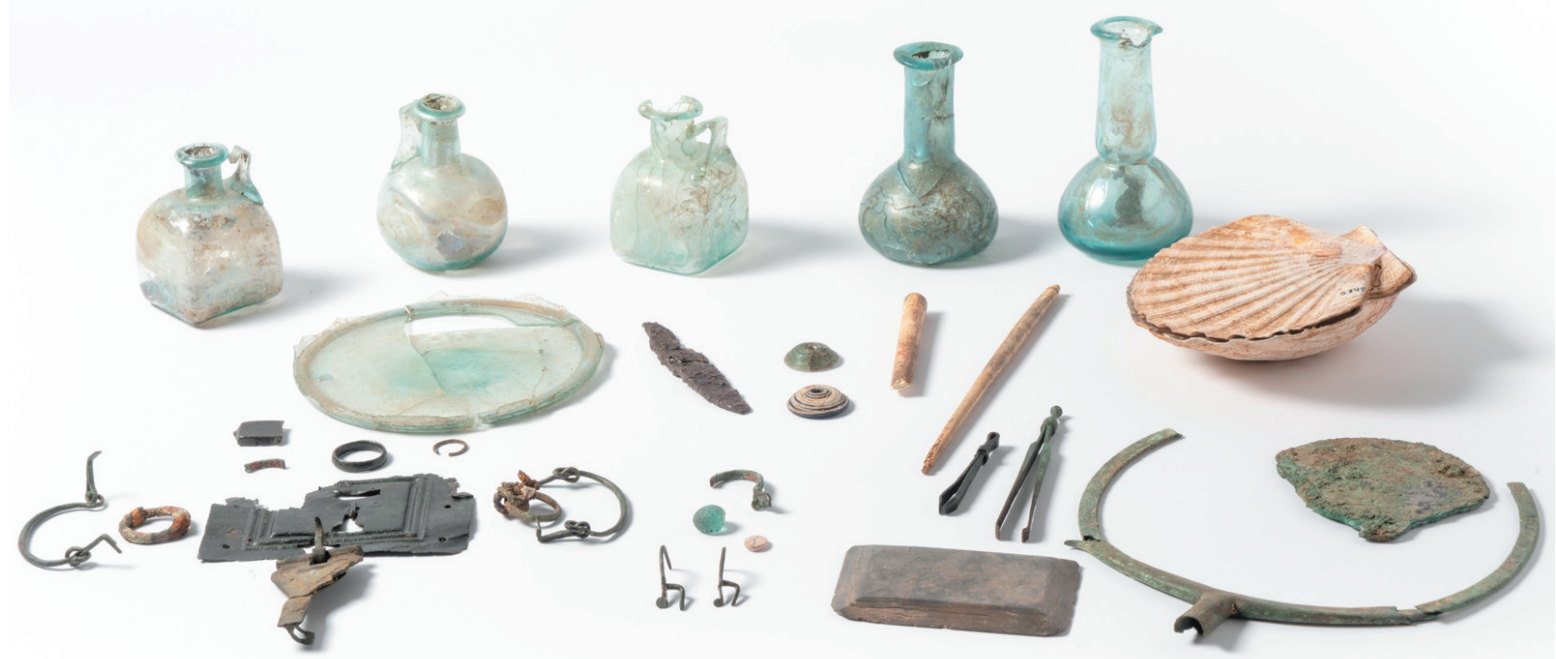

Fig. 7

Depósito funerario de la tumba ${ }^{\circ}$ 3, procedente de la Zona de El Silo (Necrópolis oriental). Foto: L. Plana. Archivo MNAR. 
( $\mathrm{n}^{\circ}$ inv. 5744), dos pinzas de bronce ( $\mathrm{n}^{\circ}$ inv. 5794 y 5795), un espejo de bronce dorado ( $\mathrm{n}^{\circ}$ inv. 5778 y 5796), y el ejemplar de Pecten maximus como contenedor. Además, también pertenecían al depósito los apliques en bronce de una caja, entre ellas la cerradura ( $n^{\circ}$ inv. 5792 y 5793) así como dos grupos de asas ( $n^{\circ}$ inv. 5790, 5791, 5793 y 5785) y distintas anillas, que completarían una caja realizada en material perecedero como la madera. Esta caja contendría parte de los objetos de tocador y adornos, así como los ungüentarios y botellas de vidrio que completaban el depósito ( $\mathrm{n}^{\mathrm{o}}$ inv. 5818 al 5823), al modo de elementos de otras cajas conocidas para contener perfumes y cosméticos en el ámbito del mundus muliebris (Giordano y Casale, 2007: 22-25).

El ajuar debió pertenecer a una mujer por el tipo de objetos relacionados. Como ya se ha indicado, la coticula no es privativa del ámbito de la medicina, sector bien conocido en el caso de Augusta Emerita (Bejarano Osorio, 2015), sino que estos objetos también eran usados para la preparación de productos de belleza (Andreu Pintado, 2012-2013: 185-202). Probablemente el Pecten maximus encontrado en este depósito pudiera haber sido usado como contenedor de productos cosméticos.

Inv. CE6312. Bivalvo completo (figs. 8a y b).

Inv. CE6487. Valva derecha. Pieza fragmentada en el perímetro. Conserva una perforación antrópica central, también fragmentada.

Inv. CE6488. Valva derecha. Pieza rota en el lateral.

Necrópolis conocida como "Viviendas protegidas". Siglo I d.C.

Álvarez Sáenz de Buruaga, 1948: 42, Lam V, 3.
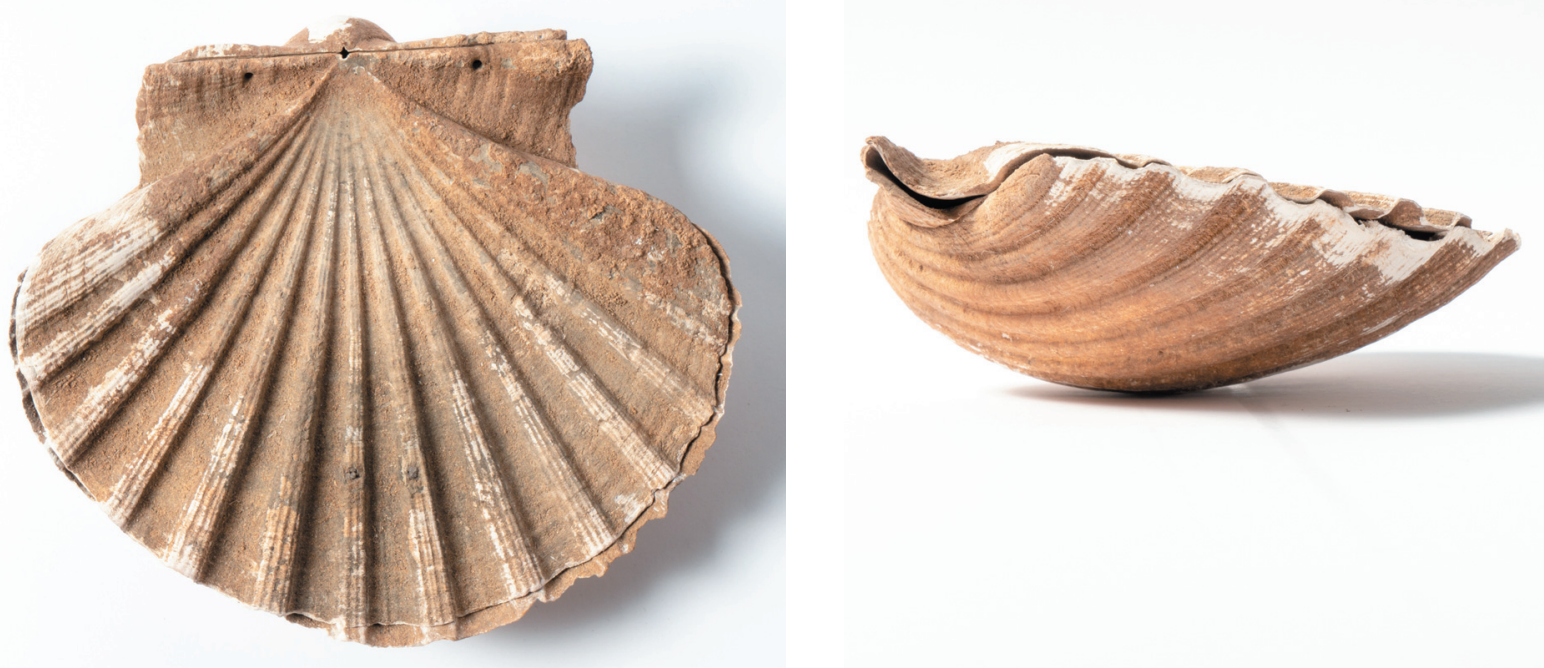

Figs. 8 a y $b$

Pecten maximus (L.), n ${ }^{\mathrm{o}}$ inv. CE6312. Foto: Archivo MNAR. 
El bivalvo completo presenta sendos orificios en ambas lengüetas dorsales. Ha perdido las anillas que sujetarían las dos piezas. Hacia el centro de la valva izquierda conserva dos orificios con lengüetas de plata embutidas, que serían la sujeción del asa de apertura, que no se ha conservado.

El Pecten completo formaba parte de un depósito especialmente lujoso, localizado dentro de una urna de plomo: un ungüentario de vidrio azul, un huso de hueso o removedor y anillo de oro con entalle decorado (fig. 9).

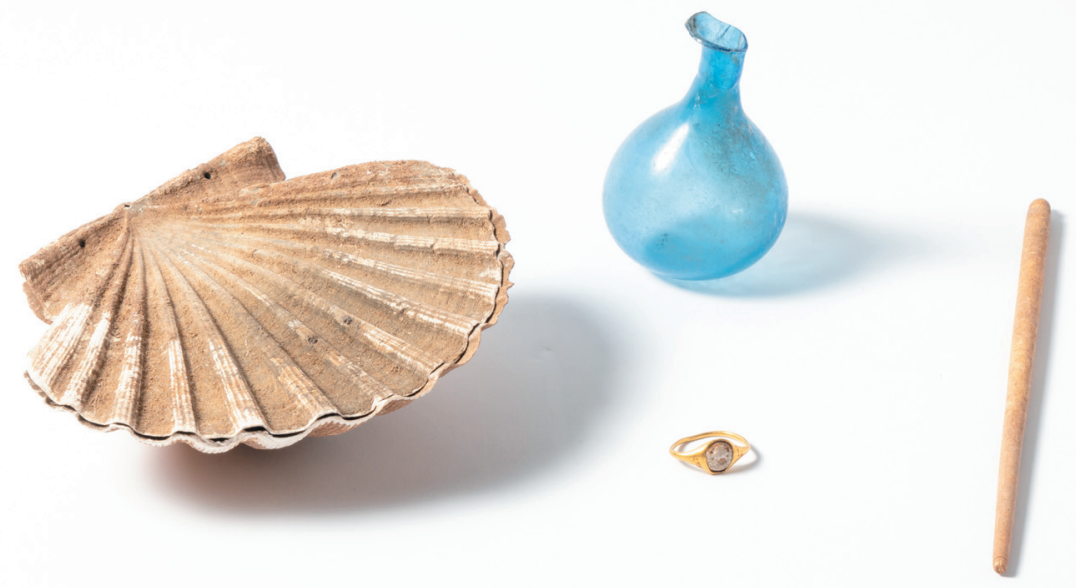

Fig. 9

Depósito funerario de la necrópolis conocida como "Viviendas protegidas".

Foto: L. Plana. Archivo MNAR.

Además, del mismo lugar, ingresan otras tres valvas de molusco, de las que sin embargo fueron inventariadas solo dos ( $n^{\circ}$ inv. 6487 y 6488) (Álvarez Sáenz de Buruaga, 1948: 42). La primera de ellas presenta un orificio central en la valva, probablemente de origen antrópico.

Inv. CE8051. Bivalvo completo.

Inv. CE8052. Bivalvo completo fragmentado.

Necrópolis del Albarregas. Corchera extremeña.

Álvarez Sáenz de Buruaga, 1953: 4.

Los dos ejemplares ingresan dentro de un lote procedente de un área de necrópolis bien conocida al nordeste de la ciudad, pero sin poder clasificar la composición de los distintos ajuares. Es significativo cómo aparece reflejado en la Memoria el ingreso de "unos trozos de pintura rosa" junto a los dos bivalvos (Álvarez 


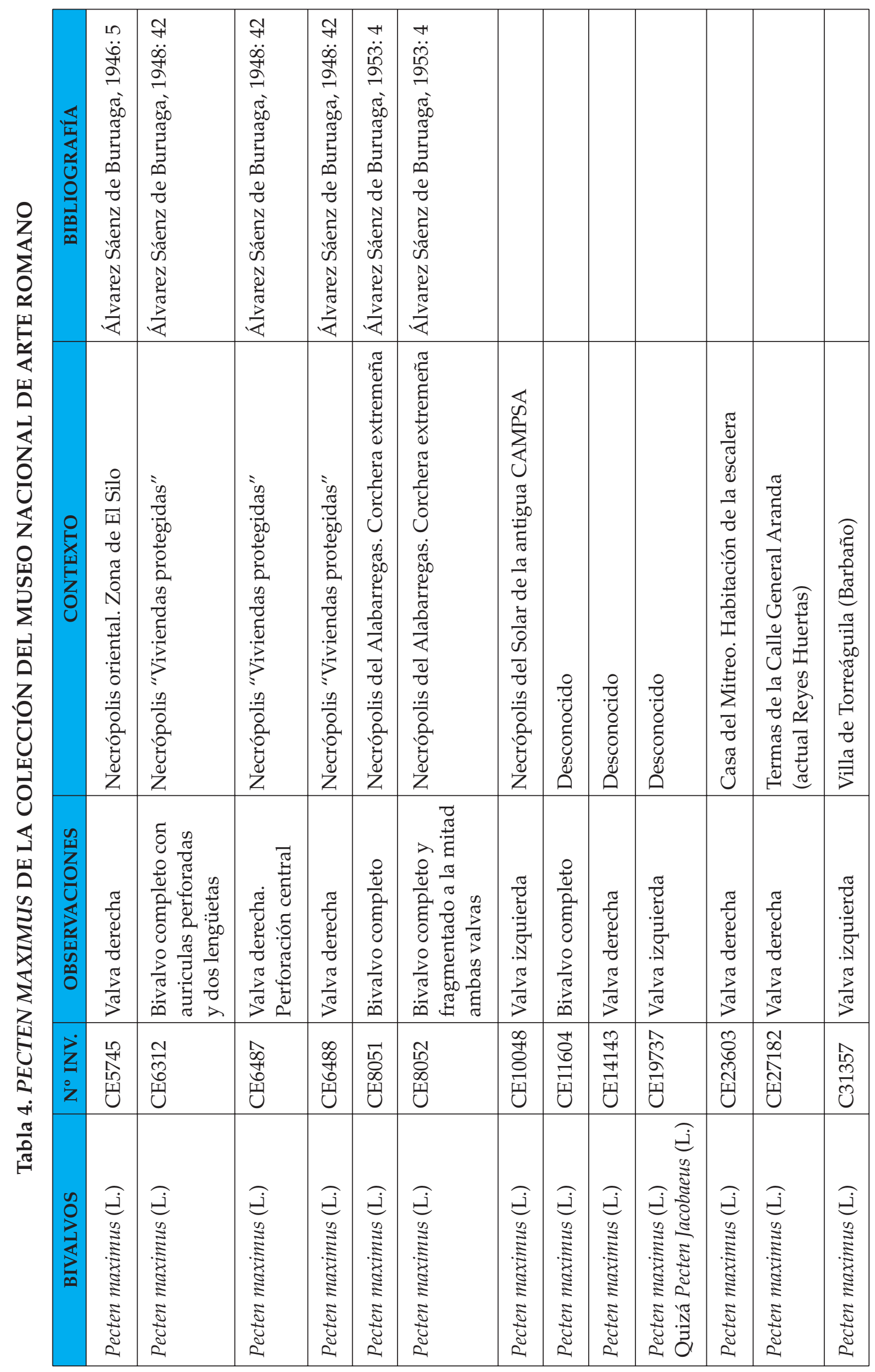


Sáenz de Buruaga, 1953: 4). Quizá se refiera al producto cosmético que contenía alguna de estas piezas, ya que en el inventario del Museo este ingreso no aparece consignado.

Inv. CE10048. Valva izquierda fragmentada en uno de los extremos.

Solar de la antigua CAMPSA. Zanja $n^{\circ} 57$.

En la documentación de ingreso en el MNAR se señala que perteneció a la "Sepultura de una niña" sin indicar más datos.

Ingresó provisionalmente el 27/06/1953 por entrega de Serra Rafols y de manera permanente el 02/08/1967.

Estos ejemplares de Pecten maximus que conservan ambas valvas están relacionados con su uso como contenedores en el ámbito del aseo y la cosmética de la mujer romana, como atestigua su inclusión dentro de los ajuares femeninos, incluso su modificación para formar tapa y recipiente, evidenciado en el caso del ejemplar $\mathrm{n}^{\circ}$ inv. 5745 e incluso el hallazgo relacionado con pintura rosa del ejemplar $\mathrm{n}^{\mathrm{o}}$ inv. 10048.

Estos casos se incluyen dentro de una moda bien conocida, en el que las conchas son empleadas como joyeros o como contenedores de cosméticos desde época sumeria (Horne y Zettler, 1998: 145). En época romana, la asociación de la concha con la mujer a través de la diosa Venus, nacida de la espuma del mar y llevada a la orilla sobre una concha, diosa del amor y de la belleza, añade nuevas connotaciones a un uso que debía ser tradicionalmente habitual.

En concreto, el Pecten maximus o Pecten jacobaeus es usado de manera habitual como elemento contenedor de productos cosméticos y perfumes (Giordano y Casale, 2007: 22). En Pompeya y Herculano se han identificado un total de 101 valvas, correspondientes a 72 individuos. De ellos, 6 tenían orificios practicados en las lengüetas dorsales, al igual que en el caso emeritense, y otros 3 ejemplares tenían otros sistemas de articulación, contando con su uso como estuches (Reese, 2002: 303-304). La documentación más antigua en la villa de Pisanella, cita un total de 10 valvas en cuyo interior se conservaba restos de ungüentos colorantes (Pasui, 1897: 551). El bivalvo reproducido por Virgili, procedente de la colección del Museo Nazionale de Taranto, presenta las lengüetas dorsales horadadas y unidas por anilla y un asa de plata en la valva izquierda (Virgili, 1989: 81, fig. 80). Este sistema sería el que tendría el bivalvo del MNAR procedente del ajuar de "Viviendas protegidas".

La alta popularidad del empleo de la concha en el ámbito de la toilette femenina llevó a la producción de lo que pueden ser considerados esqueuomorfos, esto es reproducciones del original, realizados en materiales nobles como el ámbar o la plata. La imitación de bivalvos en estos materiales produjo piezas exquisitas, que formalmente reproducen no solo la forma de la concha marina, sino también las adaptaciones realizadas para su uso como estuches. En los casos más evidentes, se perforan las lengüetas y se inserta una anilla para la articulación de la tapa, y en otros también se dispone un asa en la valva superior para facilitar su apertura. 
Este es el caso de la concha de ámbar ( $n^{\circ}$ inv. 168192) perteneciente al depósito funerario que acompañaba a la conocida "Momia de Grottarossa", un enterramiento localizado dentro de un sarcófago de mármol con un individuo femenino joven datado en la segunda mitad del siglo II d.C. (Battaglia, 1983) y que se conserva en el Museo Nazionale Romano-Palazzo Massimo. El depósito es un espléndido repertorio de objetos lujosos. Entre las piezas de ámbar hay una cajita en forma de bivalvo, con la pieza contenedora destacando por la talla de costillas radiales, mientras que la pieza superior, la valva que hace de tapa, es plana. En ambas piezas, se han practicado orificios en las lengüetas y se ha insertado un hilo de oro cerrado sobre sí mismo, para dar articulación al conjunto.

Otro ejemplo de esqueuomorfo de bivalvo, esta vez en plata, es el estuche $\left(\mathrm{n}^{\mathrm{o}}\right.$ inv. 414066) que forma parte del depósito funerario hallado en la tumba $\mathrm{n}^{\mathrm{o}} 2$ del corredor de Vallerano, datado en la segunda mitad del siglo II d.C. (Bedini, Testa y Catalano, 1995: 319-331). El depósito se exhibe hoy en el Museo Nazionale RomanoPalazzo Massimo y se compone de un espejo en plata, dos acus en ámbar y la caja realizada en lámina de plata en dos piezas, imitando la forma de bivalvo. En esta ocasión, la imitación de la morfología del Pecten maximus es evidente, con la valva derecha dispuesta como contenedor, marcando las costillas radiales, y la valva izquierda, en la parte superior, plana y marcando también las costillas. Ambas piezas se encuentran horadadas en las lengüetas, con un hilo de plata inserto enrollado sobre sí mismo para cerrar y para formar la bisagra que da movilidad al conjunto.

En la colección del Museo de Mérida se conservan dos estuches de plata en forma de concha, depositados por el Consorcio de la Ciudad Monumental de Mérida. Uno de ellos conserva solo una valva (n inv. 158/2/24 - DO2012/3/3) (Márquez Pérez, 2012: 148), que en su morfología reproduce un concepto de concha general, sin que pueda ser relacionado con una especie concreta. Por su parte, el estuche compuesto por dos piezas ( $n^{\circ}$ inv. 158/4/35 y 158/4/36 - DO2012/3/6) (Márquez Pérez, 2012: 164) está realizado sobre fina lámina de plata. La pieza inferior es de forma circular y un umbo marcado en la base, para facilitar su estabilidad, mientras que la superior tiene forma de valva genérica. En ambos casos, su ligazón como estuches, en este caso destinados probablemente a joyeros, parece una interpretación válida a tenor de los precedentes comentados.

34 Finalmente, también pertenece a la colección del MNAR una venera en ámbar con tritón marino grabado en su interior ( $\mathrm{n}^{\mathrm{o}}$ inv. 10081) (figs. 10a y b), que forma parte de un depósito funerario excepcional perteneciente a una mujer localizado en el interior de un sarcófago de plomo y datado en la primera mitad del siglo I d.C. (Barrero Martín, 2017: 172, fig. 2). Varias piezas singulares de ámbar pertenecen a este depósito, entre ellas la venera, que en su parte exterior presenta talladas las costillas radiales, mientras que en el interior alberga la figura de un tritón marino. Este tipo de piezas es representativo del gusto por estas piezas en ámbar, conocidas en yacimientos que jalonan la llamada Ruta del Ámbar como las del Museo de Aquileia (Calvi, 2005: 103-108, Lám. 74-75). 

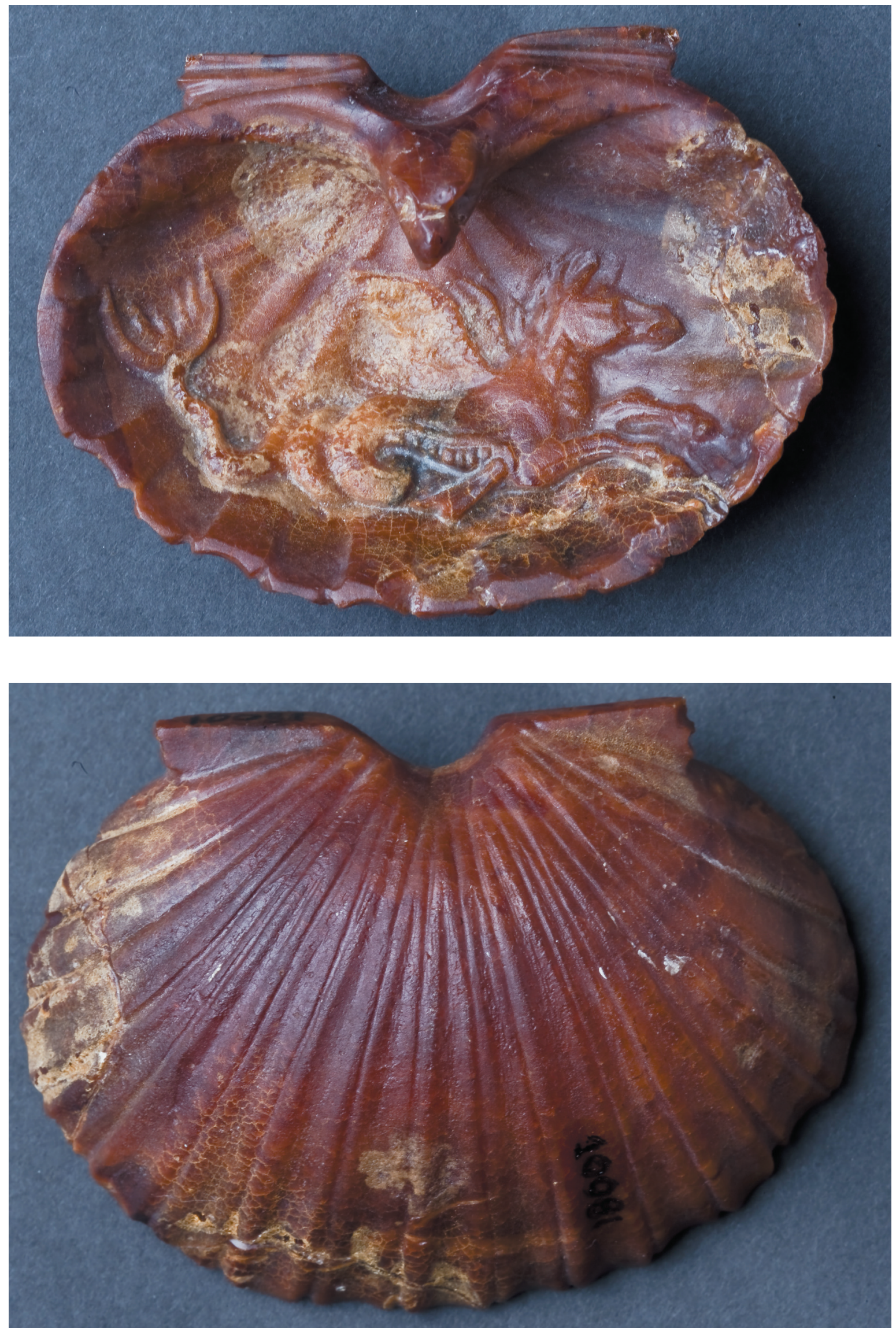

Figs. $10 a$ y $b$

Anverso y reverso de la venera de ámbar con tritón marino, $\mathrm{n}^{\circ}$ inv. 10081. Foto: Archivo MNAR. 


\section{BIBLIOGRAFÍA}

ALFARO GINER, C. (2013), "Purple and Aristocracy: Colour, blood and luxury as social identifiers in Antiquity", en C. Alfaro Giner, J. Ortiz García y M. J. Martínez García (eds.), Luxury and Dress. Political Power and Appearance in the Roman Empire and its Provinces, 75-98, Valencia.

ALFARO GINER, C. y TÉBAR MEGÍAS, E. (2004), “Aspectos históricos, económicos y técnicos de la producción de púrpura en la Ibiza romana", en C. Alfaro, J. P. Wild y B. Costa (eds.), Purpureae Vestes Actas del I Symposium Internacional sobre Textiles y Tintes del Mediterráneo en época romana, 195-210, Valencia.

ÁLVAREZ SÁENZ DE BURUAGA, J. (1946), "Museo Arqueológico de Mérida (Badajoz)”, Memorias de los Museos Arqueológicos Provinciales. 1945, 4-10, Madrid.

- (1948), "Museo Arqueológico de Mérida (Badajoz)", Memorias de los Museos Arqueológicos Provinciales. 1947, 39-45, Madrid.

- (1953), "Museo Arqueológico de Mérida (Badajoz)", Memorias de los Museos Arqueológicos Provinciales. 1952, 2-10, Madrid.

ANDREU PINTADO, J. (2012-2013), “De mundo muliebre: sobre tres coticulae romanas procedentes de Los Bañales (Uncastillo, Zaragoza)", Turiaso, nº 21, 185-202.

BARRERO MARTÍN, N. (2017), “La colección de orfebrería, glíptica y materiales nobles del Museo Nacional de Arte Romano", en N. Barrero y A. Velázquez (eds.), XXX Años en la vida de un Museo. Homenaje a José María Álvarez Martínez, 171-176, Mérida.

BATTAGLIA, G. B. (1983), Corredi funerari di età imperiale e barbarica nel Museo Nazionale Romano, Roma.

BEDINI, A., TESTA, C. y CATALANO, P. (1995), “Un sepolcreto di epoca imperiale a Vallerano", Archeologia Laziale XII-1, Quaderni di archeologia etrusco-italica, 12, 319-331.

BEJARANO OSORIO, A. M. (2015), La medicina en la Colonia Augusta Emerita, Serie Ataecina 9 , Mérida.

CALVI, M. C. (2005), Le ambre Romane di aquileia, Aquileia.

FABIÁO, C. (2014), "La creación de la provincia romana de Lusitania”, en J. M. Álvarez Martínez (ed.), Augusto y Emerita, 63-77, Mérida.

FERNÁNDEZ URIEL, P. (2010), Púrpura, del mercado al poder, Madrid.

FINET, Y. y OLIVE, C. (2004), “I molluschi marini nell'alimentazione gallo-romana della Gallia Transalpina", en M. A. Borrello (ed.), Conchiglie e Archeologia. Preistoria Alpina 40 (2004), supplemento 1: 107-114.

GIORDANO, C. y CASALE, A. (2007), Perfumes, unguents and hairstyles in Pompeii, $2^{\mathrm{a}}$ ed., Roma.

GOFAS, S., MORENO, D y SALAS, C. (coords.) (2011), Moluscos marinos de Andalucía. Volumen II, pp. i-xii y 343-798, Málaga.

HORNE, L. C. y ZETTLER, R. L. (1998), Treasures from the Royal Tombs of Ur, Pennsylvania.

MÁRQUEZ PÉREZ, J. (2012), “'Objeto de tocador' y 'Caja con tapadera'”, en El Consorcio y la Arqueología Emeritense. De la excavación al Museo, catálogo de la exposición, 148 y 164, Mérida. 
PASQUI, A. (1897), La villa pompeiana della Pisanella presso Boscoreale, Monumenti dell'Accademia dei Lincei, VII, Roma. https:/ / digi.ub.uni-heidelberg.de/diglit/monant1897/ 0207.

RODRÍGUEZ-HIDALGO, A. et al. (2013), “Un ejemplar de Cypraea pantherina en una tumba Alto imperial de Augusta Emerita", Zephyros. Revista de Prehistoria y Arqueología, Vol. LXXII, 183-193, Salamanca.

SABIO GONZÁLEZ, R. (2012), Catálogo de la colección de hierros del Museo Nacional de Arte Romano, Colección Cuadernos Emeritenses, nº 37, Mérida.

SÁEZ ROMERO, A. y GUTIÉRREZ LÓPEZ, J. M. (2014), “'Trompas de Tritón’ en ambientes productivos de Gadir: el caso de la factoría de salazones de pescado Puerto-19", en J. J. Cantillo, D. Bernal y J. Ramos (eds.), Moluscos y púrpura en contextos arqueológicos atlántico-mediterráneos. Nuevos datos y reflexiones en clave de proceso histórico. Actas de la III Reunión Científica de Arqueomalacología de la Península Ibérica, 161-176, Cádiz.

VIRGILI, P. (1989), Acconciature e maquillage, colección Vita e costumi dei romani antichi, 7, Roma. 